\title{
Anthropometrics, Metabolic Syndrome, and Mortality Hazard
}

\author{
Nir Y. Krakauer $\mathbb{D}^{1}$ and Jesse C. Krakauer $\mathbb{D}^{2}$ \\ ${ }^{1}$ Department of Civil Engineering, The City College of New York, New York, NY, USA \\ ${ }^{2}$ Metro Detroit Diabetes and Endocrinology, Southfield, MI, USA \\ Correspondence should be addressed to Nir Y. Krakauer; mail@nirkrakauer.net
}

Received 10 January 2018; Revised 24 May 2018; Accepted 17 June 2018; Published 12 July 2018

Academic Editor: Gordon Fisher

Copyright ( 2018 Nir Y. Krakauer and Jesse C. Krakauer. This is an open access article distributed under the Creative Commons Attribution License, which permits unrestricted use, distribution, and reproduction in any medium, provided the original work is properly cited.

\begin{abstract}
Independent indices (height, body mass index, a body shape index, and hip index) derived from basic anthropometrics have been found to be powerful predictors of mortality hazard, especially when the attributable risks are summed over these indices to give an anthropometric risk index (ARI). The metabolic syndrome (MS) is defined based on the co-occurrence of anthropometric, clinical, and laboratory criteria and is also widely employed for evaluating disease risk. Here, we investigate correlations between ARI and MS in a general population sample, the United States Third National Health and Nutrition Examination Survey. Baseline values of ARI and MS were also evaluated for their association with mortality over approximately 20 years of follow-up. ARI was found to be positively correlated with each component of MS, suggesting connections between the two entities as measures of cardiometabolic risk. ARI and MS were both significant predictors of mortality hazard. Although the association of ARI with mortality hazard was stronger than that of MS, a combined model with both ARI and MS score as predictors improved predictive ability over either construct in isolation. We conclude that the combination of anthropometrics and clinical and laboratory measurements holds the potential to increase the effectiveness of risk assessment compared to using either anthropometrics or the current components of MS alone.
\end{abstract}

\section{Introduction}

In 2009, an international task force recognized metabolic syndrome (MS) as a critical component in addressing cardiovascular and mortality risk around the globe [1]. The diagnosis of MS is based on co-occurrence of hypertension (a biophysical clinical measurement); elevated triglycerides, low high-density cholesterol (HDL), and hyperglycemia (laboratory measures); and elevated waist circumference (WC, an anthropometric measurement). Though there are differences in detail between definitions of MS, above-threshold values of each component are typically scored as one point, with a total score of 3 or above indicative of MS. The construct of MS has succeeded in raising awareness among professionals and the public of cardiometabolic risk at the individual and population levels and focusing attention on correcting abdominal obesity and insulin resistance and continues to be the focus of extensive research.

WC is the anthropometric component of the MS definition, and some authors even consider above-cutpoint WC values to be mandatory for diagnosis of MS. WC conceptually is considered a measure of abdominal obesity, but statistically it differs little from the even more widely used body mass index (BMI), as the correlation between the two in large population studies is typically close to 0.9 . Given this high correlation, BMI has even been taken to replace WC for the definition of MS in cohorts where WC data were unavailable [2]. A derivative of WC and hip circumference (HC) that is also taken to indicate abdominal obesity is $\mathrm{WC} / \mathrm{HC}$ ratio [3-6], which has lesser, but still substantial correlation with BMI of $\sim 0.4$ [7].

A line of research that responds to these concerns about the independence of anthropometric criteria has defined a body shape index (ABSI), based on a power-law expression that relates $\mathrm{WC}$ to height and weight (or equivalently height and BMI) [8]. Height (H), BMI, and ABSI then are complementary and independent indices that express the information provided by the basic measures of weight, height, and WC. Similarly, a hip index (HI) was defined that normalizes HC for BMI [7]. 
ABSI and HI, unlike BMI, show strong sex and age dependence. Accordingly, the risk attributable to ABSI and $\mathrm{HI}$ is best expressed after transforming the raw values, for example to $Z$ scores adjusted for age and sex $[7,9]$. Taking advantage of the approximate statistical independence of the indices $\mathrm{H}, \mathrm{BMI}, \mathrm{ABSI}$, and $\mathrm{HI}$, an anthropometric risk indicator (ARI) was introduced, which combines hazard ratios attributable to $Z$ scores of the multiple independent indices and results in improved discrimination of mortality risk compared to using any one index in isolation $[7,10]$.

MS is known to be a risk factor for all-cause mortality, as well as onset of cardiovascular disease and diabetes [11], although whether it improves prediction over just using some of its individual components continues to be investigated $[2,12,13]$. Similarly, the anthropometric indices combined into ARI, particularly ABSI, have been shown to predict mortality hazard and morbidity onset [14-25].

BMI and ABSI have been shown to correlate with the components of MS [26-35]. However, there is limited information on how anthropometric risk (as measured by ARI) overlaps with metabolic risk (as measured by MS score) in populations.

In this study, we aim to answer two major questions. First, how do anthropometric indices based on H, W, WC, and $\mathrm{HC}$ correlate with MS in a general population sample? Second, how do anthropometry-based risk and MS complement each other as predictors of mortality hazard?

\section{Methods}

2.1. Data. The Third National Health and Nutrition Examination Survey (NHANES III) sampled the civilian noninstitutionalized USA population during 1988-1994 using a cluster approach, with some groups of public health interest (children, the elderly, black and Mexican-American people) deliberately oversampled [36]. Mortality outcomes for adult subjects were available from the National Center for Health Statistics with follow-up through 2011 (17-23 years of follow-up). We analyzed NHANES III public-use data for all nonpregnant adults (age 18 and over) with the required measurements and mortality follow-up. About half of the NHANES III cohort were examined in the morning, and hence have the fasting triglyceride and glucose measurements that are used to define MS.

2.2. ARI and MS. Anthropometric indices were calculated as follows $[7,8,37]$ :

$$
\begin{aligned}
\mathrm{BMI} & \equiv \mathrm{W} \cdot \mathrm{H}^{-2}, \\
\mathrm{ABSI} & \equiv \mathrm{WC} \cdot \mathrm{H}^{5 / 6} \cdot \mathrm{W}^{-2 / 3}, \\
\mathrm{HI} & \equiv \mathrm{HC} \cdot\left(\frac{\mathrm{H}}{\langle\mathrm{H}\rangle}\right)^{0.310} \cdot\left(\frac{\mathrm{W}}{\langle\mathrm{W}\rangle}\right)^{-0.482},
\end{aligned}
$$

where $\langle H\rangle=166 \mathrm{~cm}$ and $\langle\mathrm{W}\rangle=73 \mathrm{~kg}$ are average values included in the definition as scaling factors.

The anthropometric index values for the NHANES III

\begin{tabular}{|c|c|}
\hline Component & Criteria \\
\hline Waist & $\begin{array}{l}\text { Waist circumference above } 102 \mathrm{~cm} \text { for men or } 88 \mathrm{~cm} \\
\text { for women. }\end{array}$ \\
\hline $\mathrm{BP}$ & $\begin{array}{c}\text { Systolic blood pressure at or above } 130 \mathrm{mmHg} \text { or } \\
\text { diastolic blood pressure at or above } 85 \mathrm{mmHg} \text { or } \\
\text { self-reported to be using blood pressure } \\
\text { medications. }\end{array}$ \\
\hline TG & Fasting serum triglycerides at or above $150 \mathrm{mg} / \mathrm{dL}$. \\
\hline HDL & $\begin{array}{l}\text { Serum high-density lipoprotein cholesterol under } \\
40 \mathrm{mg} / \mathrm{dL} \text { for men, } 50 \mathrm{mg} / \mathrm{dL} \text { for women. }\end{array}$ \\
\hline Glu & $\begin{array}{l}\text { Fasting plasma glucose level at or above } 110 \mathrm{mg} / \mathrm{dL} \\
\text { or self-reported to be taking pills for diabetes. }\end{array}$ \\
\hline
\end{tabular}
cohort are converted to $Z$ scores by subtracting the age and
TABLE 1: Metabolic syndrome components.

Abbreviations for and definitions of metabolic syndrome components used in this study. Each component is scored 1 if the criteria for it are met and 0 otherwise. A total score of 3 or above defines metabolic syndrome.

sex specific mean and dividing by the standard deviation [7]. Penalized spline Cox proportional hazard regressions on the subset of NHANES III that did not have the data needed to determine MS score was used to estimate the natural logarithm of the mortality hazard as a function of each anthropometric index taken alone. Then, these estimated log hazard ratios (resp. designated here $\mathrm{hH}, \mathrm{hBMI}, \mathrm{hABSI}$, and hHI) are computed for the $Z$ score values of each subject in NHANES III and summed to give ARI. The estimated mortality hazard for each combination of anthropometric indices, as a fraction of the population mean hazard, is exp(ARI), so that ARI of 0 connotes population-average risk, while positive ARI connotes above-average risk and negative ARI below-average risk [7]. An online calculator that converts anthropometrics to $Z$ scores and gives ARI and its components is available at https://www.nirkrakauer.net/sw/ari-calculator.html.

As previously done for NHANES III [38, 39], MS was defined following the Third Report of the National Cholesterol Education Program Adult Treatment Panel (ATP III) [40]. This relies on the presence or absence (scored 1/0) of each of five components: abdominal obesity (defined using WC), hypertension, hypertriglyceridemia, low high-density lipoprotein (HDL) levels, and hyperglycemia. The exact criteria used are given in Table 1. The summed score can range between 0 and 5, with a score of 3 or above constituting MS.

2.3. Prediction Models and Analysis. The considered mortality predictors in Cox proportional hazard modeling were the anthropometric index (H, BMI, ABSI, and $\mathrm{HI})$ hazard ratio natural logarithms and their sum, the ARI; and the MS components (coded 0-1), MS score (0-5), and MS occurrence $(0-1)$. The resulting predictive models considered are listed and explained in Table 2. In line with previous analyses of NHANES III [7], each prediction model also includes black race (coded 0-1) and sex. Age was implicitly included, being the timescale in the Cox model [8]. We used the provided sample weights for the morning subsample [36] so that our results would be better estimates for associations with mortality hazard in the general USA population.

As in [7], the main measure of relative predictive performance was AIC difference score, $\Delta_{i}$. For the best-performing 
TABle 2: Predictive models considered.

\begin{tabular}{|c|c|}
\hline Model & Description \\
\hline Base & No anthropometric or MS predictors. \\
\hline ARI & ARI as a predictor. \\
\hline MS & MS occurrence as a predictor. \\
\hline MS score & MS score as a predictor. \\
\hline $\mathrm{ARI}+\mathrm{MS}$ & ARI and MS occurrence as predictors. \\
\hline ARI + MS score & ARI and MS score as predictors. \\
\hline ARI + MSx score & $\begin{array}{l}\text { ARI and MS score (excluding Waist) as predictors. Excluding the WC component from the MS } \\
\text { score was hypothesized to be reasonable when considering it alongside ARI since the BMI and } \\
\text { ABSI components of ARI already correlate strongly with WC. }\end{array}$ \\
\hline MS components & $\begin{array}{l}\text { The } 5 \text { MS components as individual predictors. This tested the relative utility of the components } \\
\text { of MS, which could suggest refinements of its definition for testing in future work. }\end{array}$ \\
\hline ARI + MS components & ARI and the 5 MS components (Table 1) as individual predictors. \\
\hline ARI + MSx components & ARI and the 4 MS components (excluding Waist) as individual predictors. \\
\hline
\end{tabular}

Models for predicting mortality that were compared in this study. MS: metabolic syndrome; ARI: anthropometric risk index; WC: waist circumference; BMI: body mass index; ABSI: a body shape index.

TABle 3: Correlations in NHANES III.

\begin{tabular}{|c|c|c|c|c|c|c|c|c|c|c|c|c|}
\hline & $\mathrm{hH}$ & hBMI & hABSI & $\mathrm{hHI}$ & ARI & Waist & $\mathrm{BP}$ & TG & HDL & Glu & MS score & MS \\
\hline $\mathrm{hH}$ & 1 & -0.015 & -0.012 & -0.009 & -0.015 & 0.074 & 0.030 & -0.051 & -0.014 & -0.027 & 0.008 & 0.006 \\
\hline hBMI & & 1 & 0.032 & 0.080 & 0.775 & 0.388 & 0.116 & 0.104 & 0.123 & 0.100 & 0.284 & 0.215 \\
\hline hABSI & & & 1 & 0.050 & 0.613 & 0.258 & 0.025 & 0.120 & 0.112 & 0.047 & 0.193 & 0.148 \\
\hline hHI & & & & 1 & 0.321 & 0.122 & 0.075 & 0.077 & 0.063 & 0.110 & 0.147 & 0.128 \\
\hline ARI & & & & & 1 & 0.464 & 0.117 & 0.164 & 0.170 & 0.127 & 0.355 & 0.274 \\
\hline Waist & & & & & & 1 & 0.242 & 0.231 & 0.230 & 0.193 & 0.652 & 0.514 \\
\hline $\mathrm{BP}$ & & & & & & & 1 & 0.202 & 0.033 & 0.231 & 0.584 & 0.438 \\
\hline TG & & & & & & & & 1 & 0.325 & 0.204 & 0.655 & 0.597 \\
\hline HDL & & & & & & & & & 1 & 0.120 & 0.584 & 0.482 \\
\hline Glu & & & & & & & & & & 1 & 0.520 & 0.461 \\
\hline MS score & & & & & & & & & & & 1 & 0.828 \\
\hline MS & & & & & & & & & & & & 1 \\
\hline
\end{tabular}

Correlation coefficients among NHANES III nonpregnant adults. hH, hBMI, hABSI, and hHI refer to hazard ratio logarithms based on functional relationships between mortality and the $\mathrm{Z}$ scores of the respective anthropometric measures height, body mass index, a body shape index, and hip index. ARI is the sum of these 4 quantities. The metabolic syndrome score MS score is the sum of scores for the waist circumference, blood pressure, triglyceride, highdensity lipoprotein, and glucose components defined in Table 1. Metabolic syndrome MS is defined as a score of 3 or more.

model (with lowest AIC) $\Delta_{i}=0$, while other models have positive $\Delta_{i}$ [41]. $\Delta_{i}>6$ indicated models that perform significantly worse than the best-performing model (at the 95\% confidence level) as mortality predictors for the sampled population [17]. We also calculated coefficients $R^{2}$, denoting the proportion of variation in mortality explained by the predictors of each model, so that higher $R^{2}$ suggests a model with greater explanatory power [42]. Another measure of model performance considered was concordance $(C)$, defined as the fraction of pairs of individuals in the sample for which the one modeled to be at greater risk actually died sooner [43]. Concordance ranges from 0 to 1 , with 0.5 the expected value for models with no skill and higher values indicating models that are more skillful at explaining variation in survival. To better understand the relationship between ARI, MS, and their components in the NHANES III population, we also show and discuss the correlation coefficients between them.

\section{Results}

There were 5221 nonpregnant adults in NHANES III who had recorded all the measurements needed to evaluate the anthropometric indices and MS components, out of whom 1564 (30\%) died during follow-up. Based on the definition used, 1449 people had MS at baseline, for an MS prevalence of $28 \%$. Mean ARI was near zero $(-0.01)$, with a standard deviation of 0.23 .

Correlation coefficients between the ARI-component hazard ratios based on $\mathrm{H}, \mathrm{BMI}, \mathrm{ABSI}$, and $\mathrm{HI}$ are consistently very low in magnitude (under 0.1 ), which suggests that the anthropometric indices chosen do measure statistically independent components of mortality risk (Table 3). ARI is the sum of these components, and their respective correlations with ARI show that BMI is the largest contributor to anthropometric mortality risk in NHANES III, followed by ABSI and then $\mathrm{HI}$, with $\mathrm{H}$ having negligible value for predicting mortality. The MS components, in turn, are intercorrelated, with correlation coefficients typically around 0.2 , consistent with their being parts of a larger syndrome that nevertheless each add independent information (Table 3 ). They each have correlations of $0.5-0.7$ with their sum, the MS score, and 0.4-0.6 with MS occurrence, with TG being the best-correlated single component (Table 3 ).

ARI correlates positively with each of the MS components, with the best correlation being with Waist. In fact, 
ARI correlates better with the MS components than any one ARI component does. ARI has a correlation of 0.36 with MS score and 0.27 with MS (Table 3 ). Anthropometric mortality risk is thus associated with MS, but not as closely associated with MS as any of the MS definition components are.

The fitted coefficients and performance indicators of the proportional hazard models for mortality prediction are given in Table 4 . The presence of MS increased mortality hazard by $37 \%$ ( $95 \%$ confidence interval: $22-54 \%$, model MS in Table 4). MS score was a better population predictor than MS occurrence, with each MS component present increasing mortality hazard by $15 \%$ (10-20\%, model MS score). Separating the individual MS components suggests that Waist and TG are not significantly associated with mortality, while $\mathrm{BP}, \mathrm{HDL}$, and Glu are significantly and about equally associated with mortality (model MS components).

The predictive model with ARI (model ARI) significantly outperformed the models with only MS occurrence, MS score, or MS components. However, a model with both ARI and MS performed even better, with both ARI and MS remaining as significant predictors (model ARI + MS). ARI could also be combined with MS components, whereupon $\mathrm{BP}, \mathrm{HDL}$, and Glu remained significant mortality predictors (model ARI + MS components). In that case, the Waist component of MS was just as well omitted (models ARI + MSx score and ARI + MSx components), both because ARI already has WC as an input and because Waist's association with mortality risk in this cohort was not significant.

Overall, among the models considered here, ARI + MSx components, ARI + MS components, and ARI + MSx score were statistically tied for best predicting mortality hazard as measured by $\Delta_{i}$. While the MS score significantly outperformed MS occurrence as a mortality predictor, there was not a firm basis for giving different weights to the MS components to improve mortality prediction, as the performances of MS components and MS score and ARI + MSx components and ARI + MSx score, respectively, were statistically tied (Table 4).

\section{Discussion}

Here, we for the first time evaluated, for mortality prediction in the general population, the combination of a systematically selected set of independent anthropometrics (H, BMI, ABSI, and HI, whose respective attributable hazards were summed to give ARI) with MS. We found that although ARI was the best single mortality predictor and was positively correlated with all MS components, the clinical and laboratory data that contribute to the MS score could be used synergistically with ARI to further improve mortality prediction. Such individualized risk information could potentially be useful in a variety of clinical contexts for guiding personalized medical care [44-46].

There are some limitations to our study. Our cohort was relatively small in size, limiting statistical power, because many of the NHANES III sample did not have the fasting glucose and triglyceride measurements needed to evaluate MS. The long follow-up for mortality of approximately 20 years is a strength, but it is possible that associations of
TABLE 4: Mortality hazard association with body measures and metabolic syndrome in NHANES III.

\begin{tabular}{|c|c|c|c|c|c|}
\hline Model & $\Delta_{i}$ & $R^{2}$ & $C$ & Predictor & HR \\
\hline Base & 97.3 & 0.0148 & 0.543 & & \\
\hline ARI & 27.1 & 0.0426 & 0.600 & ARI & $2.93(2.30-3.73)$ \\
\hline MS & 71.2 & 0.0257 & 0.563 & MS & $1.37(1.22-1.54)$ \\
\hline MS score & 55.1 & 0.0318 & 0.582 & MS score & $1.15(1.10-1.20)$ \\
\hline $\mathrm{ARI}+\mathrm{MS}$ & 19.1 & 0.0464 & 0.604 & $\begin{array}{l}\text { ARI } \\
\text { MS }\end{array}$ & $\begin{array}{l}2.65(2.06-3.40) \\
1.22(1.08-1.37)\end{array}$ \\
\hline \multirow[t]{2}{*}{$\begin{array}{l}\text { ARI + MS } \\
\text { score }\end{array}$} & 10.2 & 0.0498 & 0.610 & ARI & $2.52(1.95-3.25)$ \\
\hline & & & & MS score & $1.10(1.05-1.15)$ \\
\hline \multirow[t]{2}{*}{$\begin{array}{l}\text { ARI + MSx } \\
\text { score }\end{array}$} & 5.5 & 0.0516 & 0.610 & ARI & $2.62(2.05-3.36)$ \\
\hline & & & & MSx score & $1.13(1.08-1.19)$ \\
\hline \multirow[t]{4}{*}{$\begin{array}{l}\text { MS } \\
\text { components }\end{array}$} & 49.9 & 0.0369 & 0.598 & Waist & $1.12(0.99-1.27)$ \\
\hline & & & & $\mathrm{BP}$ & $1.27(1.10-1.45)$ \\
\hline & & & & $\begin{array}{l}\text { TG } \\
\text { HDL }\end{array}$ & $\begin{array}{l}0.94(0.82-1.07) \\
1.23(1.08-1.40)\end{array}$ \\
\hline & & & & Glu & $1.31(1.15-1.49)$ \\
\hline \multirow[t]{6}{*}{$\begin{array}{l}\text { ARI + MS } \\
\text { components }\end{array}$} & 1.3 & 0.0562 & 0.617 & ARI & $2.68(2.07-3.49)$ \\
\hline & & & & Waist & $0.95(0.83-1.08)$ \\
\hline & & & & $\mathrm{BP}$ & $1.26(1.10-1.44)$ \\
\hline & & & & TG & $0.93(0.81-1.06)$ \\
\hline & & & & $\mathrm{HDL}$ & $1.23(1.08-1.40)$ \\
\hline & & & & Glu & $1.25(1.09-1.43)$ \\
\hline \multirow[t]{5}{*}{$\begin{array}{l}\text { ARI + MSx } \\
\text { components }\end{array}$} & 0 & 0.0560 & 0.620 & ARI & $2.59(2.02-3.33)$ \\
\hline & & & & $\mathrm{BP}$ & $1.25(1.09-1.44)$ \\
\hline & & & & TG & $0.92(0.81-1.05)$ \\
\hline & & & & $\mathrm{HDL}$ & $1.22(1.07-1.38)$ \\
\hline & & & & Glu & $1.24(1.09-1.42)$ \\
\hline
\end{tabular}

Results of Cox proportional hazard modeling for mortality risk in NHANES III with the linear predictors shown. All models also included as predictors sex and race. The hazard ratios are given with $95 \%$ confidence intervals. $\Delta_{i}=$ Akaike information criterion score difference relative to the bestperforming model shown (see Methods for details); $R^{2}=$ measure of explained variation; $C=$ concordance; $H R=$ hazard ratio.

anthropometrics and MS components with mortality hazard have changed over time so that these findings would not be fully applicable to current patients. Possible time changes in associations with mortality have been most fully studied for BMI, with inconclusive results so far $[47,48]$. As well, the ATP III definition of MS we used is one that has been employed in previous analyses of NHANES III [38, 39, 49], but many definitions have been proposed, with no single consensus $[1,50]$. While most patients retain their MS classification across definitions [51], in some cases morbidity and mortality associations were affected by the definition used [13, 52].

We found that hypertension, hyperglycemia, and low HDL are the main drivers of the association of MS with mortality hazard in NHANES III. Some studies have found hyperglycemia to be the component of MS most associated with mortality $[2,13]$. The strength of the mortality association with MS found in NHANES III is comparable to that seen in other cohorts [11]. 
It would be interesting to compare the risk associations seen with ARI and MS in the NHANES III national USA sample with those from other countries. WC and BMI cutoffs for cardiometabolic risks may vary between ethnicities $[53,54]$, although ABSI, for example, has been found to have comparable associations as a mortality predictor across cohorts from several continents $[21-25,55,56]$. ARI and MS could also be considered for prediction of morbidity such as cardiovascular disease and diabetes, for which the relative power of MS would be expected to be greater [11, 12].

Given the weak performance of a WC cutoff for determining mortality risk, replacing the Waist component in the definition of MS by a more sensitive anthropometric indicator of abdominal obesity could be worth exploring. Possible candidates are the $\mathrm{WC} / \mathrm{H}$ ratio $[15,57-59]$, which is linked to body roundness in an elliptical model of the human body [60] and ARI itself (at least the sum of the BMI and ABSI risks, which show the largest correlations with WC). Similarly, given the lack of association of high TG with mortality, one could also consider elimination of the TG component in the definition of MS in favor of other measures such as elevated low-density lipoprotein cholesterol [61] or TG/HDL ratio [62]. Larger cohorts and a fuller range of health outcomes would probably be necessary to definitively show the merits of these proposals.

\section{Conclusions}

In summary, we found that anthropometric parameters and factors included in the definition of metabolic syndrome, while not uncorrelated, can function synergistically as predictors of mortality hazard, potentially improving individualized risk assessment compared to using either set of predictors in isolation.

\section{Data Availability}

The NHANES III data used to support the findings of this study are publicly available online from the United States National Center for Health Statistics

\section{Conflicts of Interest}

The authors declare that they have no conflicts of interest.

\section{References}

[1] K. G. M. M. Alberti, R. H. Eckel, S. M. Grundy et al., "Harmonizing the metabolic syndrome: a joint interim statement of the International Diabetes Federation Task Force on Epidemiology and Prevention; National Heart, Lung, and Blood Institute; American Heart Association; World Heart Federation; International Atherosclerosis Society; and International Association for the Study of Obesity," Circulation, vol. 120, no. 16, pp. 1640-1645, 2009.

[2] A. Younis, R. Goldkorn, I. Goldenberg et al., "Impaired fasting glucose is the major determinant of the 20-year mortality risk associated with metabolic syndrome in nondiabetic patients with stable coronary artery disease," Journal of the American Heart Association, vol. 6, no. 11, 2017.
[3] T. Pischon, H. Boeing, K. Hoffmann et al., "General and abdominal adiposity and risk of death in Europe," New England Journal of Medicine, vol. 359, no. 20, pp. 2105-2120, 2008.

[4] J. L. Kuk and C. I. Ardern, "Influence of age on the association between various measures of obesity and all-cause mortality," Journal of the American Geriatrics Society, vol. 57, no. 11, pp. 2077-2084, 2009.

[5] H. Petursson, J. A. Sigurdsson, C. Bengtsson, T. I. L. Nilsen, and L. Getz, "Body configuration as a predictor of mortality: comparison of five anthropometric measures in a 12 year follow-up of the Norwegian HUNT 2 study," PLoS One, vol. 6, no. 10, Article ID e26621, 2011.

[6] WHO, Waist Circumference and Waist-Hip Ratio: Report of a WHO Expert Consultation, World Health Organization, Geneva, Switzerland, 2011.

[7] N. Y. Krakauer and J. C. Krakauer, "An anthropometric risk index based on combining height, weight, waist, and hip measurements," Journal of Obesity, vol. 2016, Article ID 8094275, 9 pages, 2016.

[8] N. Y. Krakauer and J. C. Krakauer, "A new body shape index predicts mortality hazard independently of body mass index," PLoS One, vol. 7, no. 7, Article ID e39504, 2012.

[9] N. Y. Krakauer and J. C. Krakauer, "Expansion of waist circumference in medical literature: potential clinical application of a body shape index," Journal of Obesity and Weight Loss Therapy, vol. 4, no. 2, p. 216, 2014.

[10] N. Y. Krakauer and J. C. Krakauer, "Untangling waist circumference and hip circumference from body mass index with a body shape index, hip index, and anthropometric risk indicator," Metabolic Syndrome and Related Disorders, vol. 16, no. 4, pp. 160-165, 2018.

[11] E. S. Ford, "Risks for all-cause mortality, cardiovascular disease, and diabetes associated with the metabolic syndrome," Diabetes Care, vol. 28, no. 7, pp. 1769-1778, 2005.

[12] A. M. McNeill, W. D. Rosamond, C. J. Girman et al., "The metabolic syndrome and 11-year risk of incident cardiovascular disease in the atherosclerosis risk in communities study," Diabetes Care, vol. 28, no. 2, pp. 385-390, 2005.

[13] O. Mayer, J. Bruthans, J. Seidlerová et al., "Prospective study of metabolic syndrome as a mortality marker in chronic coronary heart disease patients," European Journal of Internal Medicine, vol. 47, pp. 55-61, 2017.

[14] D. R. Boniface, "A new obesity measure based on relative waist circumference-how useful is it?," European Journal of Public Health, vol. 23, no. 1, p. 16, 2013.

[15] X. Song, P. Jousilahti, C. D. A. Stehouwer et al., "Comparison of various surrogate obesity indicators as predictors of cardiovascular mortality in four European populations," European Journal of Clinical Nutrition, vol. 67, no. 12, pp. 1298-1302, 2013.

[16] A. P. Kengne, J. W. J. Beulens, L. M. Peelen et al., "Noninvasive risk scores for prediction of type 2 diabetes (EPICInterAct): a validation of existing models," Lancet Diabetes and Endocrinology, vol. 2, no. 1, pp. 19-29, 2014.

[17] N. Y. Krakauer and J. C. Krakauer, "Dynamic association of mortality hazard with body shape," PLoS One, vol. 9, no. 2, Article ID e88793, 2014.

[18] K. Dhana, C. Koolhas, J. Schoufour et al., "Association of anthropometric measures with fat and fat-free mass in the elderly: the Rotterdam study," Maturitas, vol. 88, pp. 96-100, 2016.

[19] K. Dhana, M. Kavousi, M. Arfan Ikram, H. W. Tiemeier, A. Hofman, and O. H. Franco, "Body shape index in comparison with other anthropometric measures in prediction of 
total and cause-specific mortality," Journal of Epidemiology and Community Health, vol. 70, no. 1, pp. 90-96, 2016.

[20] M. Bozorgmanesh, M. Sardarinia, F. Hajsheikholeslami, F. Azizi, and F. Hadaegh, "CVD-predictive performances of "a body shape index" versus simple anthropometric measures: Tehran lipid and glucose study," European Journal of $\mathrm{Nu}$ trition, vol. 55, no. 1, pp. 147-157, 2016.

[21] K. Sözmen, B. Ünal, S. Sakarya et al., "Association of anthropometric measurement methods with cardiovascular disease risk in Turkey," Dicle Medical Journal, vol. 43, no. 1, pp. 99-106, 2016.

[22] Y. Sato, S. Fujimoto, T. Konta et al., "Body shape index: sexspecific differences in predictive power for all-cause mortality in the Japanese population," PLoS One, vol. 12, no. 5, Article ID e0177779, 2017.

[23] J. F. Grant, C. R. Chittleborough, Z. Shi, and A. W. Taylor, "The association between a body shape index and mortality: results from an Australian cohort," PLoS One, vol. 12, no. 7, Article ID e0181244, 2017.

[24] P. F. Rønn, M. Lucas, E. A. Laouan Sidi et al., "The obesityassociated risk of cardiovascular disease and all-cause mortality is not lower in Inuit compared to Europeans: a cohort study of Greenlandic Inuit, Nunavik Inuit and Danes," Atherosclerosis, vol. 265, pp. 207-214, 2017.

[25] M. Ji, S. Zhang, and R. An, "Effectiveness of a body shape index (ABSI) in predicting chronic diseases and mortality: a systematic review and meta-analysis," Obesity Reviews, vol. 19, no. 5, pp. 737-759, 2018.

[26] M. J. Duncan, J. Mota, S. Vale, M. P. Santos, and J. C. Ribeiro, "Associations between body mass index, waist circumference and body shape index with resting blood pressure in Portuguese adolescents," Annals of Human Biology, vol. 40, no. 2, pp. 163-167, 2013.

[27] Y. B. Cheung, “"A body shape index” in middle-age and older Indonesian population: scaling exponents and association with incident hypertension," PLoS One, vol. 9, no. 1, Article ID e85421, 2014.

[28] M. F. H. Maessen, T. M. H. Eijsvogels, R. J. H. M. Verheggen, M. T. E. Hopman, A. L. M. Verbeek, and F. de Vegt, "Entering a new era of body indices: the feasibility of a body shape index and body roundness index to identify cardiovascular health status," PLoS One, vol. 9, no. 9, Article ID e107212, 2014.

[29] W. Chung, C. Gun Park, and O. Ryu, "Association of a new measure of obesity with hypertension and health-related quality of life," PLoS One, vol. 11, no. 5, Article ID e0155399, 2016.

[30] S. Bertoli, A. Leone, N. Y. Krakauer et al., "Association of body shape index (ABSI) with cardio-metabolic risk factors: a cross-sectional study of 6081 Caucasian adults," PLoS One, vol. 12, no. 9, Article ID e0185013, 2017.

[31] M. Gentile, G. Iannuzzo, A. Mattiello, F. Rubba, S. Panico, and P. Rubba, "Association between body shape index and small dense LDL particles in a cohort of Mediterranean women: findings from Progetto ATENA," Journal of Clinical Biochemistry and Nutrition, vol. 61, no. 2, pp. 130-134, 2017.

[32] A. M. Nevill, M. J. Duncan, I. M. Lahart, and G. R. Sandercock, "Scaling waist girth for differences in body size reveals a new improved index associated with cardiometabolic risk," Scandinavian Journal of Medicine and Science in Sports, vol. 27, no. 11, pp. 1470-1476, 2017.

[33] M. G. Llinás, P. E. Janer, S. G. Agudo, R. G. Casquero, and I. C. González, "Utilidad en enfermería de diferentes índices antropométricos y analíticos para valorar la existencia de síndrome metabólico con los criterios NCEP ATPIII e IDF en población mediterránea española," Medicina Balear, vol. 32, no. 1, pp. 26-34, 2017.

[34] C. Mameli, N. Y. Krakauer, J. C. Krakauer et al., "The association between a body shape index and cardiovascular risk in overweight and obese children and adolescents," PLoS One, vol. 13, no. 1, Article ID e0190426, 2018.

[35] F. Gomez-Peralta, C. Abreu, M. Cruz-Bravo et al., "Relationship between "a body shape index (ABSI)" and body composition in obese patients with type 2 diabetes," Diabetology and Metabolic Syndrome, vol. 10, no. 1, p. 21, 2018.

[36] T. M. Ezzati, J. T. Massey, J. Waksberg, A. Chu, and K. R. Maurer, Sample Design: Third National Health and Nutrition Examination Survey, Vital and Health Statistics. Series 2, Data Evaluation and Methods Research 113, National Center for Health Statistics (US), Hyattsville, MA, USA, 1992.

[37] A. Keys, F. Fidanza, M. J. Karvonen, N. Kimura, and H. L. Taylor, "Indices of relative weight and obesity," Journal of Chronic Diseases, vol. 25, no. 6-7, pp. 329-343, 1972.

[38] E. S. Ford, W. H. Giles, and W. H. Dietz, "Prevalence of the metabolic syndrome among US adults: findings from the Third National Health and Nutrition Examination Survey," Journal of the American Medical Association, vol. 287, no. 3, pp. 356-359, 2002.

[39] Y.-W. Park, S. Zhu, L. Palaniappan, S. Heshka, M. R. Carnethon, and S. B Heymsfield, "The metabolic syndrome: prevalence and associated risk factor findings in the US population from the Third National Health and Nutrition Examination Survey, 1988-1994," Archives of Internal Medicine, vol. 163, no. 4, pp. 427-436, 2003.

[40] Expert Panel on Detection, Evaluation, and Treatment of High Blood Cholesterol in Adults, "Executive summary of the third report of the National Cholesterol Education Program (NCEP) Expert Panel on Detection, Evaluation, and Treatment of High Blood Cholesterol in Adults (Adult Treatment Panel III)," Journal of the American Medical Association, vol. 285, no. 19, pp. 2486-2497, 2001.

[41] K. P. Burnham and D. R. Anderson, "Multimodel inference: understanding AIC and BIC in model selection," Sociological Methods and Research, vol. 33, no. 2, pp. 261-304, 2004.

[42] P. Royston, "Explained variation for survival models," Stata Journal, vol. 6, no. 1, pp. 83-96, 2006.

[43] T. M. Therneau and P. M. Grambsch, Modeling Survival Data: Extending the Cox Model, Springer-Verlag, New York, NY, USA, 2000.

[44] M. A. Hamburg and F. S. Collins, "The path to personalized medicine," New England Journal of Medicine, vol. 363, no. 4, pp. 301-304, 2010.

[45] J. C. Krakauer and N. Y. Krakauer, "Combining body mass and shape indices in clinical practice," Case Reports in Medicine, vol. 2016, Article ID 1526175, 4 pages, 2016.

[46] V. Consalvo, J. C. Krakauer, N. Y. Krakauer, C. Antonio, M. Romano, and S. Vincenzo, “ABSI (A Body Shape Index) and ARI (Anthropometric Risk Indicator) in bariatric surgery. First application on a bariatric cohort and possible clinical use," Obesity Surgery, vol. 28, no. 7, pp. 1966-1973, 2018.

[47] S. Afzal, A. Tybjærg-Hansen, G. B. Jensen, and B. G. Nordestgaard, "Change in body mass index associated with lowest mortality in Denmark, 1976-2013," Journal of the American Medical Association, vol. 315, no. 18, pp. 1989-1996, 2016.

[48] Z. Wang, Y. Peng, and B. Dong, "Is body mass index associated with lowest mortality increasing over time?," International Journal of Obesity, vol. 41, no. 8, pp. 1171-1175, 2017. 
[49] E. S. Ford, W. H. Giles, and A. H. Mokdad, "Increasing prevalence of the metabolic syndrome among U.S. adults," Diabetes Care, vol. 27, no. 10, pp. 2444-2449, 2004.

[50] S. M. Grundy, H. Bryan Brewer, J. I. Cleeman, S. C. Smith, and C. Lenfant, "Definition of metabolic syndrome," Circulation, vol. 109, no. 3, pp. 433-438, 2004.

[51] E. S. Ford, "Prevalence of the metabolic syndrome defined by the International Diabetes Federation among adults in the U.S.," Diabetes Care, vol. 28, no. 11, pp. 2745-2749, 2005.

[52] H. Khosravi-Boroujeni, F. Ahmed, M. Sadeghi et al., "Does the impact of metabolic syndrome on cardiovascular events vary by using different definitions?," BMC Public Health, vol. 15, no. 1, p. 1313, 2015.

[53] R. Huxley, S. Mendis, E. Zheleznyakov, S. Reddy, and J. Chan, "Body mass index, waist circumference and waist:hip ratio as predictors of cardiovascular risk-a review of the literature," European Journal of Clinical Nutrition, vol. 64, no. 1, pp. 16-22, 2009.

[54] T. E. Matsha, A. Kengne, Y. Y. Yako, G. M. Hon, M. S. Hassan, and R. T. Erasmus, "Optimal waist-to-height ratio values for cardiometabolic risk screening in an ethnically diverse sample of South African urban and rural school boys and girls," PLoS One, vol. 8, Article ID e71133, 2013.

[55] X. Song, P. Jousilahti, C. D. A. Stehouwer et al., "Cardiovascular and all-cause mortality in relation to various anthropometric measures of obesity in Europeans," Nutrition, Metabolism and Cardiovascular Diseases, vol. 25, no. 3, pp. 295-304, 2015.

[56] D.-Y. Lee, M.-Y. Lee, and K.-C. Sung, "Prediction of mortality with a body shape index in young Asians: comparison with body mass index and waist circumference," Obesity, vol. 26, no. 6, pp. 1096-1103, 2018.

[57] L. M. Browning, S. Dong Hsieh, and M. Ashwell, "A systematic review of waist-to-height ratio as a screening tool for the prediction of cardiovascular disease and diabetes: 0.5 could be a suitable global boundary value," Nutrition Research Reviews, vol. 23, no. 2, pp. 247-269, 2010.

[58] M. Ashwell, P. Gunn, and S. Gibson, "Waist-to-height ratio is a better screening tool than waist circumference and BMI for adult cardiometabolic risk factors: systematic review and meta-analysis," Obesity Reviews, vol. 13, no. 3, pp. 275-286, 2012.

[59] W. C. Li, I. C. Chen, Y. C. Chang, S. S. Loke, S. H. Wang, and K. Y. Hsiao, "Waist-to-height ratio, waist circumference, and body mass index as indices of cardiometabolic risk among 36,642 Taiwanese adults," European Journal of Nutrition, vol. 52, no. 1, pp. 57-65, 2013.

[60] D. M. Thomas, C. Bredlau, A. Bosy-Westphal et al., "Relationships between body roundness with body fat and visceral adipose tissue emerging from a new geometrical model," Obesity, vol. 21, no. 11, pp. 2264-2271, 2013.

[61] J. Bartlett, I. M. Predazzi, S. M. Williams et al., "Is isolated low high-density lipoprotein cholesterol a cardiovascular disease risk factor?," Circulation, vol. 9, no. 3, pp. 206-212, 2016.

[62] H. Bibra, S. Saha, A. Hapfelmeier, G. Müller, and P. E. H. Schwarz, "Impact of the triglyceride/high-density lipoprotein cholesterol ratio and the hypertriglyceremic-waist phenotype to predict the metabolic syndrome and insulin resistance," Hormone and Metabolic Research, vol. 49, no. 7, pp. 542-549, 2017. 


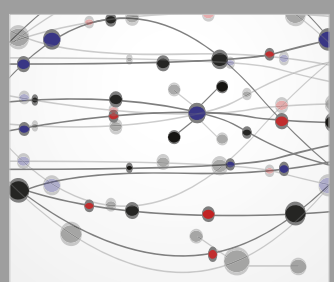

The Scientific World Journal
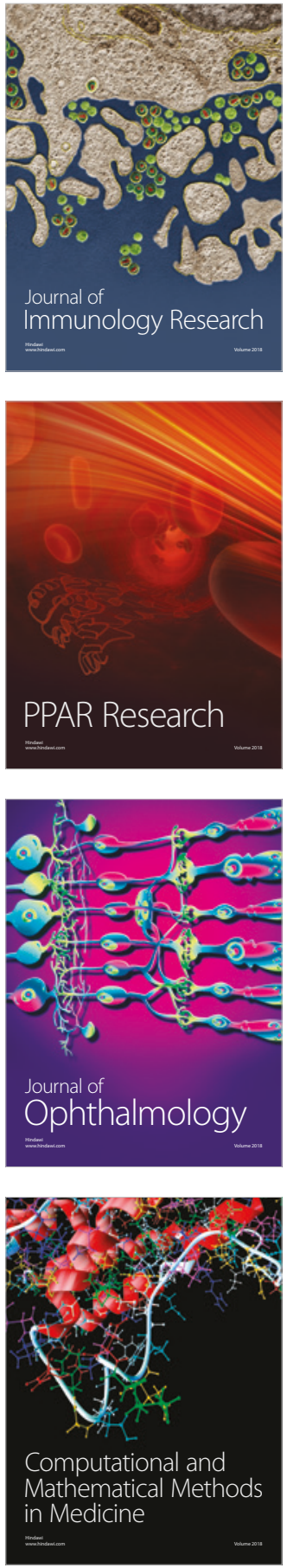

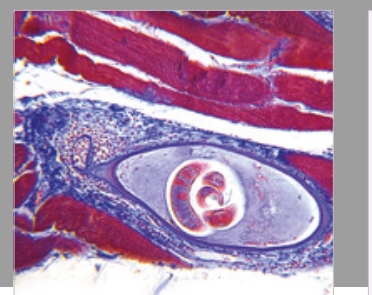

Gastroenterology Research and Practice

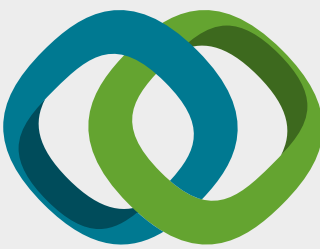

\section{Hindawi}

Submit your manuscripts at

www.hindawi.com
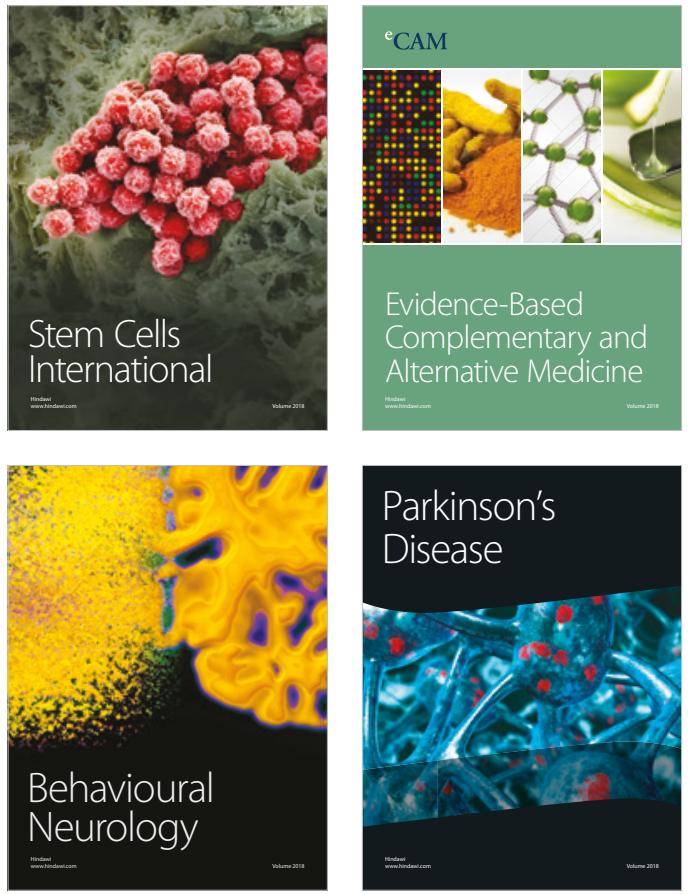

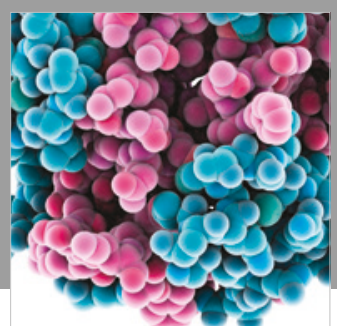

ournal of

Diabetes Research

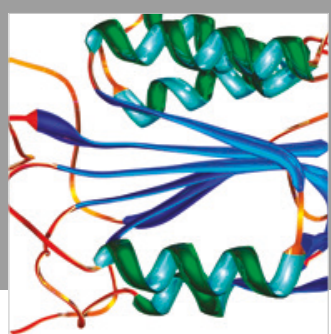

Disease Markers
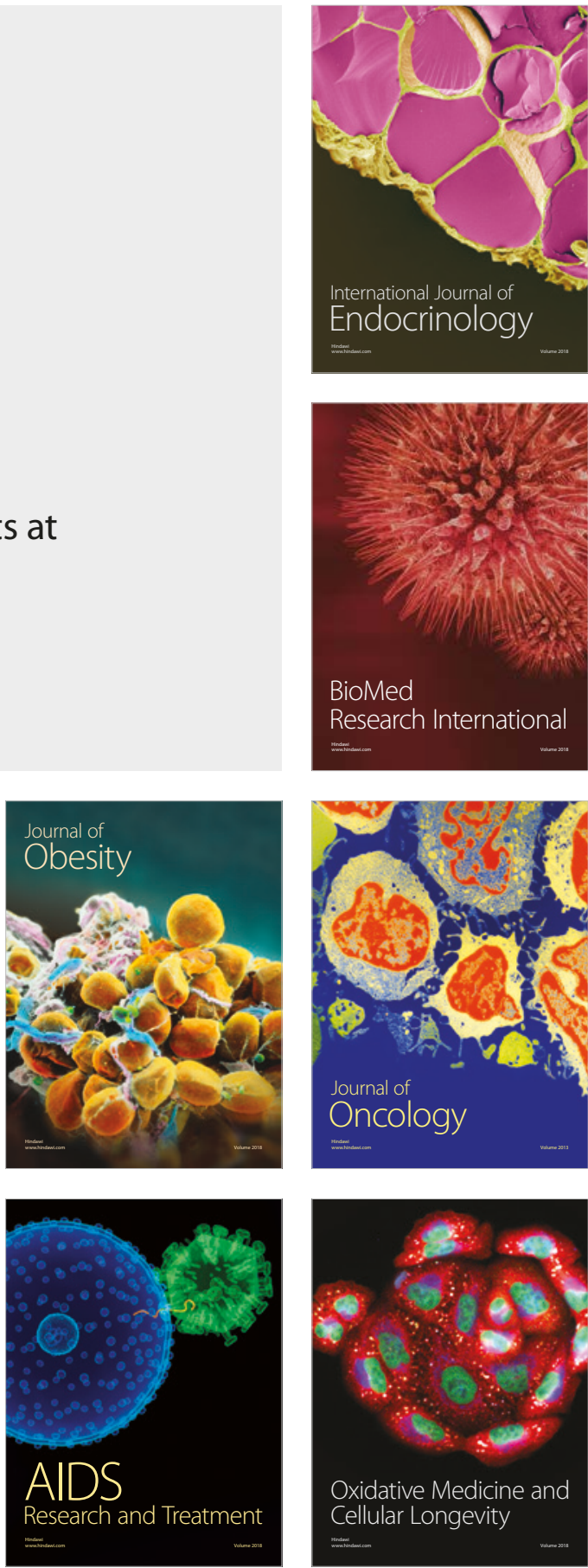